\title{
UMA PROPOSTA DE FILOSOFIA PARA A ENFERMAGEM DO HOSPITAL UNIVERSITARIO
}

\author{
Maria Cocli Campedelli* \\ Circe de Melo Ribeiro** \\ Marcia Regina Car Sarrubbo***
}

CAMPEDELLI, M. C.; RIBEIRO, C. de M.; SARRUBBO, M. R. C. Uma proposta de filosofia para a enfermagem do hospital universitário. Rev. Esc. Enf. USP, São Paulo, 15(1):17-21, 1981 .

Proposta inicial da filosofia da Divisão de Enfermagem e do Serviço de Educação Continuada do Hospital Universitário da Universidade de São Paulo.

\section{INTRODUÇÃO}

A definição de uma filosofia, para os serviços componentes de uma estratura, é recomendada em todos os tratados de administração, pois facilita a integração do pessoal e define os postulados a serem seguidos.

Em setembro de 1979, quando fomos contratadas para organizar os serviços de enfermagem do Hospital Universitário da USP (H.U.), a nossa primeira preocupação foi a leitura dos documentos preparados pela primeira comissão constituída para planejar e implantar o H.U. Assim, tomamos conhecimento de que para a referida instituição, estava preconizado o sistema do cuidado progressivo (C.P.P.), além das características de um hospital comunitário, que se completava com uma unidade de ensino e pesquisa (U.E.P.) e que deveria estar integrada com as unidades de ensino da área de saúde da USP e com as unidades sanitárias da região. Após a análise desses documentos a primeira atividade executada foi a elaboração de uma filosofia para a Divisão de Enfermagem (D.E.) e para o serviço de Enfermagem de Educação Continuada (S.E.C.).

$\mathrm{Na}$ elaboração da filosofia apresentada a seguir procuramos levar em consideração nossa experiência profissional e alguns aspectos específicos do hospital em questão, tais como: tipo de hospital, comunidade a ser assistida, serviços a serem prestados, faixa etária da população, sistema do C.P.P., integração docente-assistencial e recursos institucionais. Trata-se, evidentemente de uma proposta que deveria ser discutida e revisada em duas etapas, primeiramente com docentes da Escola de Enfermagem da USP e enfermeiras do H.U., e posteriormente com a administração superior do H.U. para aprovação.

* Professor Assistente da disciplina Introdução e Fundamentos de Enfermagem da EEUSP. Mestre em Enfermagem. Ex-Diretora da Divisão de Enfermagem do Hospital Universitário da USP.

Professor Assistente Doutor da disciplina Administração Aplicada à Enfermagem II do Curso de Pós-Graduação da EEUSP. Ex-Assistente da Diretora da Divisão de Enfermagem do Hospital Universitário da USP.

*** Auxiliar de Ensino da disciplina Enfermagem Médico-Cirúrgico I da EEUSP. Ex-Assistente da Diretora da Divisão de Enfermagem do Hospital Universitário da USP. 


\section{FILOSOFIA DA DIVISÃO DE ENFERMAGEM}

A Divisão de Enfermagem do Hospital Universitário reconhece que os hospitais, independentemente das situações que genericamente os caracterizam, cada um tem suas especialidades no que diz respeito à organização e ao funcionamento dos serviços de enfermagem. Reconhece, como conseqüência, sua responsabilidade na elaboração de uma filosofia sadia de enfermagem que caracteriza especificamente a ordem, o equilibrio, a racionalidade, a efetividade e a harmonia desejadas para a Divisão, e que constitui a essência dos valores e crenças que irão guiar todas as ações de enfermagem, técnicas ou administrativas, no Hospital Universitário, visando a prestação de serviços com o maior grau possivel de eficiência. Este objetivo a Divisão de Enfermagem considera como sinal de respeito a todas as pessoas que, governando ou pagando impostos, em moedas ou em carências, permitem a existência do Hospital Universitário.

Nós, da Divisão de Enfermagem do Hospital Universitário, conscientes de que a saúde é essencial ao crescimento e desenvolvimento completo dos Indivíduos e que a doença pode interferir nesse processo impedindo, inclusive, que as pessoas dêem a máxima contribuição possível para a vida, sua Própria, de sua Família e de sua Comunidade, e, em razão da própria finalidade do Hospital:

Reconhecemos que, como profissionais de Enfermagem, devemos contribuir para a promoção, manutenção e recuperação da saúde, empregando todos os nossos recursos técnico-científicos e habilidades na prestação de uma assistência de enfermagem aos Clientes do Hospital segundo suas necessidades, identificadas individual ou coletivamente, sem qualquer discriminação social.

Reconhecemos que a assistência ininterrupta, planejada, executada e avaliada com todo o rigor científico, em qualquer área ou setor da Enfermagem é a única forma de promover a desejada eficácia e eficiência da Divisão, com o mínimo desperdício dos recursos sociais, econômicos e materiais.

Reconhecemos a necessidade de orientação e educação dos nossos Clientes a respeito de saúde, para que possam conscientemente colaborar na recuperação da própria saúde e voltar o mais rápido possivel à vida social normal.

Reconhecemos que o bom relacionamento no trabalho e o respeito à dignidade de nossos semelhantes são condiçōes que favorecem a motivação do pessoal e permitem o funcionamento harmônico em todas as áreas e setores de Enfermagem.

Reconhecemos que a dinamização e melhoria constante do modelo assistencial de Enfermagem depende da utilização adequada dos recursos humanos, organizacionais e econômicos, para o que vêm a contribuir os sistemas programados de: desenvolvimento de pessoal, avaliação contínua de desempenho, pesquisa operacional e modernização administrativa.

Reconhecemos que há uma relação de qualidade, direta e permanente, entre o Exercício, o Ensino e a Pesquisa em Enfermagem num hospital escola, a qual deve ser intensificada pela integração docente-assistencial Hospital Universitário/ Escola de Enfermagem/Unidade de Ensino e Pesquisa. 
Com base na filosofia exposta, a Divisão de Enfermagem se propãe a:

- prestar assistência de enfermagem de padrão elevado a todos os indivíduos da comunidade registrados no hospital e sob controle terapêutico em regime de internação ou ambulatório;

- promover as condições e prover os recursos para um programa efetivo de integração docente-assistencial;

- realizar estudos, levantamentos e pesquisas de interesse para o ensino e prática da enfermagem.

\section{FILOSOFIA DO SERVIÇO DE EDUCAÇÃO CONTINUADA}

Na declaração de filosofia da Divisão de Enfermagem está implícita a integração das três atividades "fim" da enfermagem no Hospital Universitário: assistência, ensino e pesquisa, considerando que para cada uma, enquanto "fim", as demais constituem "meios", para que se possa realmente alcançar o máximo de eficiência e eficácia em todas as ações de enfermagem no Hospital Universitário. A Divisão de Enfermagem reconhece a necessidade e a obrigatoriedade da integração das três áreas de atividade; a forma e os recursos para tanto estão configurados no modelo organizacional.

A Divisão de Enfermagem delega ao Serviço de Educação Continuada todas aquelas funçōes relativas ao desenvolvimento sistemático de seu pessoal profissional e auxiliar, funções essas que vão do planejamento, execução e avaliação de programas educacionais, gerais e específicos, aos estudos relativos a técnicas, métodos e recursos didáticos. Obedecendo o modelo integrado de organização o Serviço de Educação Continuada utiliza os resultados do trabalho de enfermagem na Unidade de Ensino e Pesquisa no treinamento e capacitação, em todos os níveis, do pessoal da Divisão de Enfermagem para a prestação de assistência efetiva da enfermagem à comunidade atendida pelo Hospital Universitário, cujo padrão será continuamente objetivo de avaliação, atuando o resultado como fator de correção do processo educacional do Serviço de Educação Continuada.

O Serviço de Educação Continuada reconhece que, entre as variáveis dependentes do modelo assistencial de enfermagem, é o nível de satisfação do pessoal que reflete a consideração dada ao problema do desenvolvimento integral do ser humano como força de trabalho que merece ser tratado com toda a dignidade possível. Considerando que as necessidades básicas do ser humano estão presentes em todas as fases da vida, o Serviço de Educação Continuada exibe, na sua metodologia de planejamento dos programas educacionais e na sua organização processual, o interesse primário e direto em relação à segurança, aprovação e valorização do pessoal, garantindo o volume de conhecimentos e a oportunidade para o desenvolvimento de habilidades, como requerido e/ou necessário.

O Serviço de Educação Continuada reconhece que os recursos humanos, devidamente preparados e entrosados, respeitando-se o nível de responsabilidade de cada categoria, constituem a força maior que permitirá sejam alcançados aqueles objetivos do Hospital Universitário que ficam sob a responsabilidade da enfermagem. Considerando que no mercado de oferta de mão de obra não se en- 
contra pessoal de enfermagem como produto acabado, o Serviço de Educação Contituada reconhece como sua responsabilidade, por delegação, oferecer a todos, enfermeiras, auxiliares de enfermagem, atendentes e escriturários de enfermagem, oportunidades para completar ou iniciar sua formação técnica, atentando sempre para as características e necessidades do trabalho de enfermagem no Hospital Universitário e para o princípio de continuidade e progressividade na programação das atividades didáticas.

O Serviço de Educação Continuada acredita que:

1. o crescimento e desenvolvimento do pessoal de enfermagem leva à maior satisfação, segurança e rendimento no trabalho;

2. o pessoal de enfermagem deve estar devida e especificamente preparado para poder prestar a assistência de enfermagem, como definida pela Divisão de Enfermagem, que os pacientes internados têm direito c/ou necessidade;

3. a participação da enfermagem do Hospital Universitário, na comunidade, será tanto mais efetiva quanto mais complcta for a orientação e mais específica a educação para a saúde que os Clientes do Hospital Universitário receberem do pessoal devidamente conscicntizado e preparado para as funções de enfermagem de saúde pública;

4. quanto maior for a participação do pessoal de enfermagem na identificação de necessidades educacionais ou na elaboração, execução e avaliação de cada programa, maior será o seu grau de cfetividade;

5. as pesquisas operacionais são vitais para a maximização dos resultados e redução dos custos dos programas de Educação Continuada;

6. o planejamento, execução e avaliação dos programas são funções que devem ser levadas a efeito com participação efetiva das chefias de enfermagem do Hospital Universitário, com um adequado sistema de registro e controle das atividades desenvolvidas;

7. quanto mais alto for o padrão de assistencia de enfermagem no Hospital Universitário melhores serão as condições para o ensino e pesquisa, tanto na área de enfermagem como nas demais áreas.

A partir desta filosofia o Serviço de Educação Continuada se propõe a organizar suas atividades visando alcançar os seguintes objetivos:

1. desenvolver as habilidades e talentos criativos do pessoal de enfermagem;

2. desenvolver habilidade do pessoal profissional na resolução de problemas de enfermagem;

3. favorecer a melhor utilização dos recursos humanos na enfermagem;

4. capacitar o pessoal profissional de enfermagem para planejar, executar e avaliar a assistência aos pacientes internados e de ambulatório; 
5. oferecer oportunidade para a coparticipação do pessoal de enfermagem na elaboração de programas de atualização, revisão, avaliação e outros programs específicos;

6. preparar, experimentar e avaliar modelos operacionais de treinamento de atendentes;

7. colaborar com a Direção da Divisão de Enfermagem para oferecer ótimas condições de aprendizado de estudantes de enfermagem, coordenando programas e estágios;

8. preparar planos anuais de educação e elaborar programas com bese nas necessidades identificadas, do pessoal e da Divisão de Enfermagem;

9. analisar, avaliar e introduzir modificações na metodologia de ensino;

10. coparticipar com a enfermagem da Unidade de Ensino e Pesquisa na revisão e modernização das técnicas e procedimentos de enfermagem.

CAMPEDELLI, M. C.; RIBEIRO, C. de M.; SARRUBBO, M. R. C. The philosophy of the nursing services of the University of São Paulo Hospital. A suggestion. Rev. Esc. Enf. USP, São Paulo, 15(1):17-21, 1981.

The authors offer suggestions for the philosophy to be adapted by the Nusing Division and Continued Education Service of the University of São Paulo Hospital.

\section{BIBLIOGRAFIA}

DIMOCK, N. Filosofia da administração. Rio de Janeiro, Fundo de Cultura, 1967. 280 p.

DI VICENTI, M. Administering nursing service. 2. ed. Boston, Little Brown, 1977, $340 \mathrm{p}$.

KRON, T. Manual de enfermagem. 4. ed. Rio de Janeiro, Interamericana, 1978. 251 p.

RIBEIRO, C. de M. Organização de serviço de enfermagem. Rev. Bras. Enf., Brasília, 26 (3): 121.33, maio 1973. 